\title{
DESEMPENHO DE JARDINS CLONAIS DE OLIVEIRA (Olea europaea) EM CORTES SUCESSIVOS VISANDO A SUA PROPAGAÇÃO POR ESTAQUIA
}

\author{
João Vieira Netoํㄹ Adelson Francisco de Oliveira², Csaignon Mariano Caproni³, \\ Fabíola Villaa, Luiz Fernando de Oliveira da Silva ${ }^{5}$
}

(recebido: 8 de janeiro de 2010; aceito: 30 de novembro de 2010)

\begin{abstract}
RESUMO: O trabalho teve por objetivo avaliar o desempenho de jardins clonais de oliveira em cortes sucessivos visando a sua propagação por estaquia. Os jardins clonais foram instalados em março de 2006, em sulcos com $40 \mathrm{~cm}$ de profundidade. Foram avaliadas duas cultivares (Ascolano 315 e Arbequina) e três anos de cortes (2007, 2008 e 2009). O ensaio foi conduzido em parcelas subdivididas no delineamento de blocos casualizados com cinco repetições. As parcelas experimentais foram constituídas de três linhas, espaçadas entre si em 1,0 metro, com três plantas em cada linha, com espaçamentos de 0,5 m, totalizando nove plantas por parcela, sendo as avaliações realizadas nas três plantas mais vigorosas. As plantas foram podadas a $20 \mathrm{~cm}$ de altura do solo, após 12 meses de cultivo, sendo avaliados: rendimento em número de estacas com quatro nós/dois pares de folhas, altura da planta (m), diâmetro do tronco a $20 \mathrm{~cm}$ de altura do solo (cm), comprimento médio de ramos (m) e massa fresca total acumulada (kg). Na maioria das características avaliadas, os melhores resultados foram observados para 'Ascolano 315'. Os cortes sucessivos podem se estender por um período superior a três anos. As estimativas dos parâmetros avaliados indicam que as plantas das duas cultivares apresentaram boa resposta a rebrota.
\end{abstract}

Palavras-chave: Ascolano, Arbequina, propagação vegetativa.

\section{PERFORMANCE OF CLONAL OLIVE TREE GARDENS IN SUCCESSIVE CUTS AIMING CUTTING PROPAGATION}

\begin{abstract}
This work evaluated the performance of clonal olive tree gardens in successive cuts aiming cutting propagation. The clonal garden was installed in March 2006, in grooves $40 \mathrm{~cm}$ deep. Two cultivars (Ascolano 315 and Arbequina) were evaluated and cut in 2007, 2008 and 2009. The test was carried out in split plot in time in a randomized block design with five replications. The plots were composed of three lines, one meter spaced between them, three plants in each line, spaced 0,5 $\mathrm{m}$ from each other, totaling nine plants per plot, being evaluated only the three most vigorous plants. For evaluation, three plants were pruned 20 $\mathrm{cm}$ height above soil, after 12 months of cultivation, it was evaluated the yield of cuttings with four knots and two pairs of leaves; plants height (m), torso diameter the $20 \mathrm{~cm}$ height of the soil (cm); branches length (m); and total green mass accumulated (kg). In most features evaluated, the best results were observed in the 'Ascolano 315'. The successive cuts may be extended over a three year period. The parameter estimates indicate that plants of both cultivars y responded satisfactorily to regrowth.
\end{abstract}

Key words: Ascolano, Arbequina, vegetative propagation.

\section{INTRODUÇÃO}

A oliveira (Olea europaea) teve seu cultivo iniciado a quatro mil anos a.C. no norte do Mar Morto, expandindo-se para o Ocidente pelo Mediterrâneo. Atualmente é cultivada em praticamente todos os continentes (RALLO et al., 2005). A importância dessa cultura agrícola está relacionada principalmente com a produção de azeite de oliva.
Na região mediterrânea, em países da Comunidade Econômica Européia, a produção de azeite de oliva corresponde a 79,8\% em todo o mundo, destacando-a como maior produtora, sendo 42,9\% obtidos na Espanha, 17,5\% na Itália e 12,2\% na Grécia, além de responder por quase 80\% das exportações mundiais (MESQUITA et al., 2006).

O cultivo de oliveiras no Brasil é uma atividade agrícola recente e em expansão (OLIVEIRA et al., 2009b).

\footnotetext{
${ }^{1}$ Engenheiro Agrônomo, Pesquisador Dr. em Agronomia - Empresa de Pesquisa Agropecuária de Minas Gerais - Fazenda Experimental de Maria da Fé - Bairro Vargedo - 37517-000 - Maria da Fé, MG - joaovieira@epamig.br

${ }^{2}$ Engenheiro Agrônomo, Pesquisador Dr. em Agronomia - Empresa de Pesquisa Agropecuária de Minas Gerais - Campus da UFLA - Rodovia Lavras/Ijaci, km 02 - Cx. P. 176 - 37200-000 - Lavras, MG - adelson@epamig.br

${ }^{3}$ Engenheiro Agrônomo, Pesquisador Mestre em Agronomia - Empresa de Pesquisa Agropecuária de Minas Gerais - Av. Prefeito Tuany Toledo, 470, Sala 8 - UNIVAS - Pouso Alegre, MG - caproni@epamig.br

${ }^{4}$ Engenheira Agrônoma, Professora Dra. em Agronomia-Universidade Estadual do Oeste do Paraná -Centro de Ciências Agrárias - Rua Pernambuco, 1777, Centro - 85960-000 - Marechal Candido Rondon, PR - fvilla2003@libero.it

${ }^{5}$ Engenheiro Agrônomo, Mestrando em Agronomia - Empresa de Pesquisa Agropecuária de Minas Gerais - Fazenda Experimental de Maria da Fé Bairro Vargedo - 37517-000 - Maria da Fé, MG - luizfernando.agronomia@gmail.com
} 
Com base no volume de azeitonas importadas anualmente (214 mil ton), estima-se um mercado potencial de mudas de aproximadamente 11 milhões de unidades, para suprir o mercado interno, exigindo da pesquisa informações técnicas para a sua produção (COMPANHIA NACIONAL DE ABASTECIMENTO - CONAB, 2009).

Quanto a produção de mudas de oliveira a estaquia é o método de propagação mais utilizado. Essa técnica vem sendo aprimorada nos últimos anos, principalmente o enraizamento de estacas semilenhosas sob nebulização intermitente, e por isso é hoje amplamente utilizada em muitos países europeus (CABALLERO; DEL RIO, 2006). Porém, essa técnica requer atenção para determinados fatores que influenciam no enraizamento, como disponibilidade e tipo de material vegetativo a ser utilizado. Muitas vezes, as matrizes fornecedoras de material encontram-se em fases fenológicas desfavoráveis na formação de raízes como, por exemplo, em floração e/ ou frutificação (OLIVEIRA et al., 2009a).

A implantação de jardins clonais com o objetivo de fornecer material propagativo torna-se vantajosa, pois, além de permitir a coleta de ramos durante todo o ano, podem apresentar caráter juvenil e vigor vegetativo, características estas favoráveis ao enraizamento (CABALLERO, 1981).

Diante do exposto, objetivou-se, com o presente trabalho, avaliar o desempenho de jardins clonais de plantas de oliveira visando a sua propagação por estaquia, sob cortes sucessivos em intervalos de 12 meses, com o intuito de gerar informações sobre o ritmo de crescimento, o vigor e o rendimento propagativo.

\section{MATERIAL E MÉTODOS}

O trabalho foi conduzido na Fazenda Experimental da Epamig, localizada no município de Maria da Fé-MG, micro região da serra da Mantiqueira, sul de Minas Gerais.

O município apresenta uma classificação climática, segundo Köppen, do tipo Cwb, ou seja, clima temperado chuvoso (mesotérmico), também denominado subtropical de altitude. Caracteriza-se por apresentar uma temperatura média anual de $17^{\circ} \mathrm{C}$, temperatura média máxima de 23,3 ${ }^{\circ} \mathrm{C}$ e mínima média de $10,1{ }^{\circ} \mathrm{C}$, precipitação anual de 1.738,6 mm e altitude média de 1.276 m, com predomínio de relevo ondulado (ASSEMBLÉIA LEGISLATIVA DO ESTADO DE MINAS GERAIS - ALMG, 2005; FUNDAÇÃO JOÃO PINHEIRO, 2001).

Os jardins clonais foram instalados em março de 2006, em área previamente corrigida de acordo com análise de fertilidade para $\mathrm{pH}$ em torno de 6,0, utilizando-se calcário dolomítico (PRNT 100\%). Foram avaliadas duas cultivares de oliveira (Ascolano 315 e Arbequina) e três cortes sucessivos (março de 2007, 2008 e 2009).

O delineamento experimental utilizado foi o de parcelas subdivididas com cinco repetições. As parcelas experimentais foram constituídas de três linhas, espaçadas entre si em 1,0 metro, com três plantas em cada linha, espaçadas em $0,5 \mathrm{~m}$, totalizando nove plantas por parcela, sendo as avaliações realizadas nas três plantas mais vigorosas a fim de padronizar o material experimental.

As mudas de oliveira utilizadas no ensaio foram obtidas por enraizamento de estacas semilenhosas tratadas com Ácido Indolbutírico - AIB em câmara de nebulização intermitente. Os plantios foram realizados em sulcos com $40 \mathrm{~cm}$ de profundidade, sendo adubados 60 dias antes com $15 \mathrm{~L}$ da mistura esterco de curral + esterco de galinha, na proporção de 1:1 (devidamente misturados com a terra de plantio), enriquecidos com 1,5 kg de superfosfato simples em 1,0 m linear de sulco. Em todas as parcelas experimentais foram aplicados, mensalmente, 4,5 L de solução com adubo foliar com macro e micronutrientes na concentração de 14\% de N (amoniacal 0,7\%, nítrica 8\% e amídica 5,3\%); $4 \%$ de $\mathrm{P}_{2} \mathrm{O}_{5} ; 20 \%$ de $\mathrm{K}_{2} \mathrm{O} ; 2 \%$ de $\mathrm{Mg} ; 2 \%$ de B; e $0,05 \%$ de $\mathrm{Mn}$.

As plantas do jardim clonal receberam irrigação localizada sempre que necessário, em quantidades suficientes para manter o solo umedecido.

Para avaliação, as três plantas foram podadas a $20 \mathrm{~cm}$ de altura do solo, a cada 12 meses de cultivo, sendo avaliados o rendimento em número de estacas com quatro nós e dois pares de folhas (em torno de $12 \mathrm{~cm}$ de comprimento), a altura da planta (m), diâmetro do tronco a $20 \mathrm{~cm}$ de altura do solo (mm), comprimento médio de ramos (m) e massa fresca total acumulada $(\mathrm{kg})$.

Foi aplicada a análise de variância, com teste F, visando avaliar os efeitos principais assim como a interação entre os fatores. Para a comparação das médias foi aplicado o teste de Tukey.

\section{RESULTADOS E DISCUSSÃO}

Os resultados da análise de variância indicaram efeito significativo da interação cultivar x cortes, para diâmetro do tronco, comprimento médio de ramos e massa fresca total. Quando considerado apenas o efeito principal de cortes, houve significância para altura de planta e número de estacas, enquanto que as cultivares diferiram entre si apenas em relação ao número de estacas.

Cerne, Lavras, v. 17, n. 1, p. 117-122, jan./mar. 2011 
Com finalidade de proporcionar a normalidade dos erros experimentais, foi aplicada à transformação $(\mathrm{x}+0,5)^{1 / 2}$ para o número de estacas por planta.

A quantidade de estacas com quatro nós e dois pares de folhas retiradas da parte aérea da cultivar Ascolano 315, independentemente do efeito de cortes, foi 2,1 vezes maior do que o número de estacas obtidas da cultivar Arbequina (Figura 1).

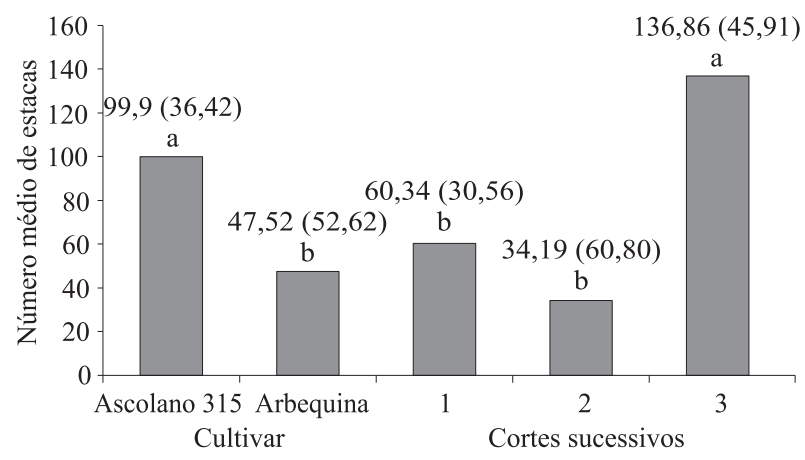

*Médias não seguidas da mesma letra diferem entre si pelo teste de Tukey a 5\% de probabilidade de erro.

Figura 1 - Valores médios do rendimento do número de estacas para cultivares de oliveira e cortes sucessivos em jardins clonais.

Figure 1 - Means of cuttings for olive tree cultivars end successive cuts in clonal gardens.

Essa diferença nas médias pode ser atribuída ao hábito de crescimento mais intenso da Ascolano 315, quando comparada com a cultivar Arbequina. Ao trabalhar com a caracterização morfológica de cultivares de oliveira do banco de germoplasma da espécie, Oliveira et al. (2006) observaram que, de todas as cultivares analisadas, a Ascolano 315 se destacou com plantas mais altas, sendo por isso considerada muito vigorosa. Estudos recentes de adaptação de cultivares no norte de Minas Gerais mostraram melhor rendimento agronômico em plantas com um ano de idade dessa mesma cultivar (OLIVEIRA et al., 2008).

Ainda é possível observar que o terceiro corte proporcionou maior número de estacas (136), indicando que as duas cultivares possuem boa capacidade de rebrota, quando submetidas a cortes sucessivos em intervalos anuais. O melhor resultado verificado no terceiro corte pode estar associado, principalmente, ao sistema radicular mais desenvolvido em relação aos cortes anteriores, condicionando a formação de ramos mais vigorosos.
A altura das plantas foi influenciada pelo número de cortes, sendo maiores no primeiro e terceiro, alcançando respectivamente 1,97 e 2,23 m de altura (Tabela 1). Oliveira et al. (2010) também verificaram efeito do número de cortes sucessivos sobre a altura de plantas de oliveira em jardins clonais obtendo plantas mais altas no primeiro e terceiro cortes, alcançado respectivamente 1,83 e 1,91 m. O maior crescimento das plantas no primeiro ano é atribuído principalmente ao vigor inicial das mudas e a menor competição por luz e nutrientes. No segundo ano, devido a intervenção do primeiro corte, há necessidade da planta estabelecer novamente o equilíbrio entre o sistema radicular, ainda em formação, e a parte aérea. No terceiro ano, já com raízes mais bem formadas, as plantas emitem brotações mais vigorosas, recuperando mais rapidamente a parte aérea.

Tabela 1 - Valores de altura média de plantas de oliveira (Olea europaea) em jardins clonais sob cortes sucessivos.

Table 1 - Average plants height of olive tree (HT, $m$ ) in clonal gardens in successive cuts.

\begin{tabular}{cc}
\hline Cortes sucessivos & Média $(\mathrm{m})$ \\
\hline 1 & $1,97 \mathrm{a}$ \\
2 & $1,25 \mathrm{~b}$ \\
3 & $2,23 \mathrm{a}$ \\
\hline
\end{tabular}

*Médias não seguidas da mesma letra diferem entre si pelo teste de Tukey a 5\% de probabilidade.

Esses resultados sugerem que os cortes sucessivos podem se estender por um período superior a três anos, sendo necessária a continuidade das avaliações experimentais até que se verifique uma redução significativa nos parâmetros avaliados, principalmente no rendimento em número de estacas, inviabilizando a manutenção do jardim clonal em escala comercial. Essa variável é considerada como um importante índice técnico, interferindo diretamente no planejamento de produção de mudas, especialmente no dimensionamento de viveiros comerciais.

Observa-se, na Tabela 2, que a cultivar Ascolano 315 superou em 65,2 \% o diâmetro do tronco da Arbequina no terceiro corte, não diferindo nos dois cortes anteriores. Em ambas as cultivares o diâmetro do tronco das plantas foi maior no terceiro corte. Segundo Del Rio e Caballero (2006), a altura e o diâmetro da planta são parâmetros que fazem referência ao vigor da árvore de oliveira, definindo o seu tamanho definitivo. Esses autores atribuem ao efeito de cultivar a principal causa da variabilidade observada para esse critério agronômico.

Cerne, Lavras, v. 17, n. 1, p. 117-122, jan./mar. 2011 
Tabela 2 - Valores de diâmetro médio do tronco (cm), comprimento médio dos ramos (m) e massa fresca total acumulada (kg) para cultivar de oliveira (Olea europaea) e cortes sucessivos em jardins clonais.

Table 2 - Means of stem diameter $(\mathrm{cm})$, branches length $(\mathrm{m})$ and total green mass accumulated $(\mathrm{kg})$ for olive tree cultivars and successive cuts in clonal gardens.

\begin{tabular}{lccccccccc}
\hline & \multicolumn{3}{c}{ Diâmetro médio do tronco $(\mathrm{cm})$} & \multicolumn{3}{c}{ Comprimento médio dos ramos $(\mathrm{m})$} & \multicolumn{3}{c}{ Massa fresca total acumulada $(\mathrm{kg})$} \\
\cline { 2 - 11 } Cultivar & \multicolumn{3}{c}{ Corte } & \multicolumn{3}{c}{ Corte } & \multicolumn{4}{c}{ Corte } \\
\cline { 2 - 10 } & 1 & 2 & 3 & 2 & 3 & 1 & 2 & 3 \\
\hline Ascolano 315 & $21,27 \mathrm{aB}$ & $26,13 \mathrm{aB}$ & $58,02 \mathrm{aA}$ & $0,78 \mathrm{aB}$ & $0,96 \mathrm{aB}$ & $1,89 \mathrm{aA}$ & $1,43 \mathrm{aB}$ & $0,75 \mathrm{aB}$ & $3,35 \mathrm{aA}$ \\
Arbequina & $12,87 \mathrm{aB}$ & $18,33 \mathrm{aB}$ & $35,12 \mathrm{bA}$ & $0,48 \mathrm{aB}$ & $1,04 \mathrm{aAB}$ & $1,30 \mathrm{bA}$ & $0,40 \mathrm{aA}$ & $0,54 \mathrm{aA}$ & $1,44 \mathrm{bA}$ \\
\hline
\end{tabular}

*Médias não seguidas da mesma letra minúscula na vertical e maiúscula na horizontal diferem entre si pelo teste de Tukey a 5\% de probabilidade.

Sendo assim, a cultivar Ascolano 315 apresentouse mais vigorosa do que a cultivar Arbequina. No entanto, esta última é muito apreciada pela produção precoce, elevada produtividade, bom rendimento graxo e excelente qualidade do azeite produzido, porém com baixa estabilidade (COUTINHO et al., 2007). Devido ao seu baixo vigor vegetativo, é amplamente utilizada em sistema de plantio superintensivo em todo mundo, especialmente na Argentina, Chile e Espanha (RIUS, 2007).

Em estudos com poda de formação da oliveira 'Cornicabra', López et al. (2009) verificaram maior diâmetro de tronco a $30 \mathrm{~cm}$ do solo em plantas no terceiro ano de corte e maior volume de copa no primeiro e segundo ano.

Quanto ao comprimento dos ramos e à massa fresca total acumulada, os resultados foram semelhantes aos observados para o diâmetro do tronco, ou seja, a cultivar Ascolano 315 apresentou maior comprimento médio de ramos e maior acúmulo de massa fresca, quando comparado a Arbequina, no terceiro corte (Tabela 2).

A importância da seleção de matrizes pelo volume da parte aérea, ausência de patógenos e susceptibilidade a doenças permitiu que a propagação vegetativa se tornasse o principal método de reprodução clonal de árvores selecionadas (HAAG, 1983), destacando a estaquia como a técnica de maior viabilidade econômica para o estabelecimento de plantios clonais de espécies florestais (PAIVA; GOMES, 1993).

O potencial de regeneração de touças em Eucalyptus é, normalmente, afetado pelas condições edafoclimáticas da região de plantio, pelas alternativas de manejo e por determinantes genéticos. A interação desses fatores pode influenciar o potencial inicial de regeneração, fazendo com que falhas, após cada corte, aumentem, resultando em oscilações ao final de cada corte de ramos (ZUFFELLATORIBAS; RODRIGUES, 2001).

Cerne, Lavras, v. 17, n. 1, p. 117-122, jan./mar. 2011
Guimarães (1994), estudando períodos de corte do jardim clonal de Eucalyptus dunnii, verificou também influência dos cortes na dimensão dos brotos vegetativos e na posterior capacidade de enraizamento das estacas. Em estudos de jardim clonal de 20 clones oriundos de matrizes híbridas de Eucalipto, Rosse et al. (1997) constataram que a capacidade de brotação das cepas e o enraizamento das estacas foram influenciados pela época de abate das árvores e pela precipitação média anual. O mesmo foi observado por Perrando e Corder (2006) em plantas de acácia-negra (Acacia mearnsii).

De acordo com os resultados obtidos, verificouse que a cultivar Ascolano 315 apresentou melhor desempenho, quando comparado a cultivar Arbequina, na maioria das características agronômicas avaliadas. Resultado semelhante foi encontrado por Oliveira (2007) em avaliações de jardins clonais com os mesmos genótipos independentemente do método de obtenção das mudas, estaquia e enxertia. Segundo Oliveira et al. (2006), esse resultado pode ser explicado pelo intenso hábito de crescimento da Ascolano 315, considerada muito vigorosa.

No entanto, salienta-se que esse comportamento diz respeito às características intrínsecas aos genótipos estudados, não sendo motivo de exclusão de um em detrimento do outro. Ambos os materiais são importantes na implantação comercial da olivicultura no sul de Minas Gerais, pois as duas cultivares estudadas destinam-se para mesa (Ascolano 315) e para produção de azeite (Arbequina). A utilização de jardins clonais para a produção de estacas vem sendo amplamente utilizada em cafeeiros, frutíferas em geral e principalmente em eucalipto, sendo o presente estudo importante para incentivar o emprego desta técnica em plantios comerciais brasileiros de oliveira. 


\section{CONCLUSÕES}

De acordo as condições em que foi desenvolvido o presente estudo e considerando os resultados obtidos conclui-se que:

- a cultivar Ascolano 315 apresentou os melhores resultados na maioria das características agronômicas avaliadas;

- existem evidências de que os cortes sucessivos podem se estender por um período superior a três anos;

- as estimativas dos parâmetros avaliados indicam que as plantas das duas cultivares apresentaram boa resposta a rebrota.

\section{AGRADECIMENTOS}

À Fundação de Amparo a Pesquisa do Estado de Minas Gerais - FAPEMIG pelo apoio financeiro na execução desse trabalho.

\section{REFERÊNCIAS}

\section{ASSEMBLÉIA LEGISLATIVA DO ESTADO DE MINAS} GERAIS. Banco de dados. Belo Horizonte, 2005. Disponível em: <http://www.almg.gov.br/index.asp?grupo=estado\&direto rio=munmg\&arquivo=municipios $>$. Acesso em: 22 jul. 2008.

\section{CABALLERO, J. M. Multiplicación del olivo por}

etaquillado semileñoso bajo nebulización. [S.l.]: INIA, 1981. (Comunicaciones INIA, Serie Producción Vegetal, 31:39).

CABALLERO, J. M.; DEL RÍO, C. Propagação da Oliveira por enraizamento de estacas semilenhosas sob nebulização. Informe Agropecuário, Belo Horizonte, v. 27, n. 231, p. 3338, mar./abr. 2006.

\section{COMPANHIA NACIONAL DE ABASTECIMENTO.}

Indicadores da agropecuária. Brasília, 2009. Disponível em: <http://www.conab.gov.br/conabweb/index.php?PAG=212>. Acesso em: 14 set. 2009.

COUTINHO, E. F.; JORGE, R. O.; COSTA, V. B. Cultivares de oliveira. In: COUTINHO, E. F. (Ed.). A cultura da oliveira. Pelotas: EMBRAPA, 2007. p. 39-49.

DEL RIO, C.; CABALLERO, J. M. Caracterização de variedades de oliveira no Banco Mundial de Germoplasma de Córdoba, Espanha. Informe Agropecuário, Belo Horizonte, v. 27, n. 231, p. 18-26, mar./abr. 2006.
FUNDAÇÃO JOÃO PINHEIRO. Anuário estatístico de Minas Gerais: 2000/2001. Belo Horizonte, 2002. 582 p.

GUIMARÃES, H. S. Clonagem em Eucalipto. Piracicaba: IPEF, 1994. Disponível em: <http://www.ipef.br/publicacoes/reuniao_ clonagem_intensiva/cap09.pdf>. Acesso em: 30 abr. 2009.

HAAG, H. P. Nutrição mineral do Eucalyptus, Pinus, Araucaria e Gmelina no Brasil. Campinas: Fundação Cargil, 1983. 101 p.

LÓPEZ, D. P.; ELCOROBARRUTIA, F. J. R.; RAMOS, N. O. Respuesta de un olivar cv. 'Cornicabra' a distintos momentos de la primera poda de formación en Ciudad Real. Disponível em: <http://www.expoliva.com/ expoliva2003/simposium/com.asp?anio=2003\&codigo=OLI $>$. Acesso em: 30 abr. 2009.

MESQUITA, D. L.; OLIVEIRA, A. F. de; MESQUITA, H. A. de. Aspectos econômicos da produção e comercialização do azeite de oliva e azeitona. Informe Agropecuário, Belo Horizonte, v. 27, n. 231, p. 7-12, 2006.

OLIVEIRA, A. F.; ANTUNES, L. E. C.; SCHUCH, M. W. Caracterização morfológica de cultivares de oliveira em coleção e considerações sobre o seu cultivo no Brasil. Informe Agropecuário, Belo Horizonte, v. 231, n. 27, p. 55-62, 2006.

OLIVEIRA, A. F.; CHALFUN, N. N. J.; ALVARENGA, A. A.; VIEIRA NETO, J.; PIO, R.; OLIVEIRA, D. L. Estaquia de oliveira em diferentes épocas, substratos e doses de AIB diluído em $\mathrm{NaOH}$ e álcool. Ciência e Agrotecnologia, Lavras, v. 33, n. 1, p. 79-85, 2009a.

OLIVEIRA, A. F.; VIEIRA NETO, J.; GONÇALVES, E. D.; ALVARENGA, A. A.; OLIVEIRA, D. L. Rendimento agronômico de variedades de oliveira (Olea europaea $\mathrm{L}$.) no norte de Minas Gerais. In: CONGRESSO BRASILEIRO DE FRUTICULTURA, 20., 2008, Vitória. Anais... Vitória, 2008. CD-ROM.

OLIVEIRA, A. F.; VIEIRA NETO, J.; GONÇALVES, E. D.; MESQUITA, D. L. Pioneirismo marca pesquisa sobre oliveira em Minas Gerais. Informe Agropecuário, Belo Horizonte, v. 30, p. 7-15, 2009b.

OLIVEIRA, A. F.; VIEIRA NETO, J.;VILLA, F.; SILVA, L. F. O. Desempenho de jardins clonais de oliveira obtidos por estaquia e enxertia em cortes sucessivos. Scientia Agraria, Curitiba, v. 11, p. 299-305, 2010.

Cerne, Lavras, v. 17, n. 1, p. 117-122, jan./mar. 2011 
OLIVEIRA, D. L. Multiplicação da oliveira através da enxertia, estaquia e ácido indolbutírico. 2007. 58 p. Dissertação (Mestrado em Fitotecnia) - Universidade Federal de Lavras, Lavras, 2007.

PAIVA, H. N.; GOMES, J. M. Propagação vegetativa de espécies florestais. Viçosa, MG: UFV, 1993. 40 p.

PERRANDO, E. R.; CORDER, M. P. M. Rebrota de cepas de Acacia mearnsii em diferentes idades, épocas do ano e alturas de corte. Pesquisa Agropecuária Brasileira, Brasília, v. 41, n. 4, p. 555-562, 2006.

RALLO, L. Variedades de olivo en España: una aproximación cronológica. In: RALLO, L.; BARRANCO, D.; CABALLERO, J. M.; DEL RÍO, C.; MARTÍN, A.; TOUS, J.; TRUJILLO, I. (Ed.). Variedades de olivo en España. Sevilla:
Consejería de Agricultura y Pesca de la Junta de Andalucía; Madrid: Ministerio de Agricultura, Pesca y Alimentación/ Mundi-Prensa, 2005. cap. 1, p. 17-44.

ROSSE, L. N.; DAVIDE, A. C.; BERTOLUCCI, F. L. G.; RAMALHO, M. P. Influência da idade e da época de abate na brotação das cepas e no enraizamento de estacas em clones de Eucalyptus sp. Cerne, Lavras, v. 3, p. 109-119, 1997.

RUIS, X. Notas sobre plantaciones superintensivas de olivo em Chile. Olint, Curicó, v. 1, n. 3, p. 12-15, 2007.

ZUFFELLATO-RIBAS, K. C.; RODRIGUES, J. D.

Relações entre épocas do ano e diferentes concentrações de ácido indol butírico no enraizamento de estacas de Eucalyptus grandis. Boletim de Pesquisa, Colombo, n. 42, p. 71-80, 2001. 